Gerión. Revista de Historia Antigua

ISSN: 0213-0181

http://dx.doi.org/10.5209/geri.68590

\title{
La aparición del término "bagauda": nuevas consideraciones sobre la hipótesis de inclusión en Kaisergeschichte y en los Xpovıкoì Kavóves de Eusebio de Cesarea
}

\author{
Raúl Serrano Madroñal ${ }^{1}$
}

Recibido: 18 de octubre de 2019 / Aceptado: 21 de enero de 2020

Resumen. Existe un consenso historiográfico a la hora de atribuir sin cuestionamiento el primer registro del término "bagauda" a Aurelio Víctor. Hacia el 358-360, el autor afro-romano plasmaba en De Caesaribus el nombre indígena que recibió la tropa capitaneada por Aelianus y Amandus en 285. Sin embargo, la Quellenforschung más reciente tiende a considerar que pudo haber un registro anterior en la no conservada $K G$. Por otro lado, sabemos que Jerónimo de Estridón tradujo, reelaboró y publicó la crónica precedente de Eusebio de Cesarea en los últimos decenios del siglo IV, donde también aparece el mismo vocablo. Si Jerónimo no se limitó a copiar sin añadidos las tablas cronológicas de Eusebio, deberíamos contemplar tanto la adición propia en base a otras fuentes como la posible inclusión del concepto que nos ocupa ya en el trabajo del obispo de Cesarea. Así pues, el artículo presente se constituye con el objetivo de refutar la última hipótesis planteada.

Palabras clave: Bagaudas; Kaisergeschichte; Eusebio de Cesarea; Aurelio Víctor; Jerónimo de Estridón.

\section{[en] The Appearance of the Term "Bagauda": New Considerations on the Hypothesis for Inclusion in Kaisergeschichte and in the Eusebius of Caesarea's Xpoviкoì Kavóveৎ}

\begin{abstract}
There is a historiographical consensus when we attribute without questioning the first record of the term "bagauda" to Aurelius Victor. By 358-360, the Afro-Roman author used in De Caesaribus the indigenous name that was received by the troop led by Aelianus and Amandus in 285. However, the most recent Quellenforschung tends to consider that an earlier record could have been written in the unconserved $K G$. We know that Saint Jerome translated, reworked and published the preceding chronicle of Eusebius of Caesarea in the last decades of the fourth century, where the same word also appears. If Jerome did not copy Eusebius' chronological tables without additions, we should consider both his own inclusion based on other sources and the possible insertion of the concept that concerns us already in the work of the Bishop of Caesarea. Thus, the present paper is constituted with the objective of refuting this last hypothesis.
\end{abstract}

Keywords: Bagaudae; Kaisergeschichte; Eusebius of Caesarea; Aurelius Victor; Jerome.

Sumario: 1. Introducción. 2. Kaisergeschichte: la fuente principal de Aurelio Víctor. 3. Kaisergeschichte: ¿una fuente utilizada por Jerónimo? 4. Los Xpovıкoì Kavóves de Eusebio de Cesarea. 5. ¿Pudo Eusebio de Cesarea usar la Kaisergeschichte? 6. ¿Pudo entonces Eusebio de Cesarea usar la palabra "bagauda"

Universidad Complutense de Madrid.

E-mail: raulserrano83@hotmail.com 
en sus Хроviкоì Kavóveৎ sin tener acceso a la Kaisergeschichte? 7. Conclusiones. 8. Referencias bibliográficas.

Cómo citar: Serrano Madroñal, R. (2020): La aparición del término "bagauda": nuevas consideraciones sobre la hipótesis de inclusión en Kaisergeschichte y en los Xроvıко̀̀ Kavóvєৎ de Eusebio de Cesarea, en Gerión 38/1, 193-205.

\section{Introducción}

El nombre de estos rebeldes aparece por primera vez en la obra de Aurelio Víctor. ${ }^{2}$ Sextus Aurelius Victor nació en el norte de África, ${ }^{3}$ probablemente poco después de $320 ;{ }^{4}$ tras recibir una cuidada formación, inicialmente en Cirta o en Cartago, y en la propia Roma con posterioridad, terminó alcanzando cargos de relevancia en la burocracia imperial hasta convertirse en gobernador consular y Praefectus urbi. ${ }^{5}$ Es plausible que residiera en Roma entre 337-357, antes de afincarse en Sirmium, donde se ganó el favor personal de Juliano en $361 .{ }^{6}$ Como gobernador de Pannonia Secunda, y por tanto miembro del ordo senatorial, fue honrado con una estatua de bronce. ${ }^{7}$ En tiempos de Teodosio I, ejerció como prefecto de la ciudad de Roma $(388-389){ }^{8}$

El breviario de biografías imperiales que compuso, seguramente iniciado en 358, cubre el período cronológico comprendido entre el principado de Augusto y el de Constancio II, aportando información sobre hechos acontecidos hasta $360 .{ }^{9}$ Conocido normalmente como De Caesaribus, estas Historiae abbreviatae parecen haber sido elaboradas por Aurelio Víctor antes de convertirse en gobernador consular.

Inmediatamente antes del famoso pasaje que menciona por vez primera a los bagaudas (39.17-20), se refería al reinado de Caro y sus descendientes. Confirmando que los bárbaros aprovecharon la muerte de Probo para invadir las provincias romanas por diversos flancos, Caro decidió enviar a su hijo mayor a defender las Galias, mientras que él mismo marchaba con Numeriano hacia el frente persa. Resulta obvio que, tras el fallecimiento de Caro y de Numeriano, Carino tuvo que dejar las Galias a toda prisa para presentarse a marchas forzadas en el Illyricum, donde acabó con la usurpación de Juliano, corrector de Venetia. A continuación alcanzó las fronteras de Mesia, donde libró combate contra Diocleciano y pereció traicionado por sus

\footnotetext{
Czúth 1965, 23; Sánchez León 1996, 28.

Starr 1956, 574.

Bird 1994, VII-IX.

Bird 1984.

Amm. Marc. 21.10.5-6: His ut in re tali tamque urgenti compositis, magistro equitum illic relicto, imperator revertitur Naessum (copiosum oppidum), de quo impraepedite cuncta disponeret, suis utilitatibus profutura. Ubi Victorem apud Sirmium visum, scriptorem historicum, exindeque venire praeceptum, Pannoniae secundae consularem praefecit, et honoravit aenea statua, virum sobrietatis gratia aemulandum, multo post urbi praefectum. Rolfe (Reed.) 2000, 136.

Rohrbacher 2002, 43.

Errington 2006, 134-135.

Aur. Vic. Caes. 42.20.
} 
propios tribunos, hastiados de su vileza. Siguiendo las palabras del relato, Aurelio Víctor nos ofrece el primer testimonio explícito registrado sobre los bagaudas. ${ }^{10} \mathrm{En}$ este contexto de luchas por el poder, Aelianus y Amandus ${ }^{11}$ levantaron en la Galia a una tropa integrada por campesinos y bandidos, ${ }^{12}$ beneficiándose de la salida de Carino y sus ejércitos en 285. Los incolae, es decir, los habitantes locales o indígenas de la región los llaman "Bagaudas". Los bagaudas ${ }^{13}$ saquearon una gran extensión de campos e intentaron asediar la mayoría de las ciudades, por lo que Diocleciano decidió enviar a las Galias a Maximiano, un hombre semiagrestis pero de probada lealtad y excelentes condiciones para comandar ejércitos. En su campaña, Maximiano pacificó toda la Galia en poco tiempo y se impuso militarmente frente a unos enemigos dispersados o derrotados en una guerra en la que destacó Carausio, un menapio conocido por sus hazañas. ${ }^{14}$

\section{Kaisergeschichte: la fuente principal de Aurelio Víctor}

Aurelio Víctor, como vemos, no es una fuente coetánea de los hechos relatados, en tanto en cuanto registró estos sucesos unos setenta y cinco años después de que ocurriesen. H. W. Bird, ${ }^{15}$ y como él buena parte de los investigadores de la materia, ${ }^{16}$ han aceptado que tanto Aurelio Víctor como Eutropio ${ }^{17}$ hicieron uso de

10 Existen tres panegíricos de Maximiano (289, 291 y 307) que se constituyen como las fuentes implícitas coetáneas sobre el levantamiento bagauda del siglo III. Empero, en ningún momento se hace uso del término específico. Galletier 1949, 27-28, 29, 52, 54-55, y 1952, 22. Mamert. Pan. Lat. 2(10)4.1-4; 5.1; 6.1; Mamert. Pan. Lat. 3(11)3.4-5; 5.3; Pan. Lat. 6(7)8.3. Sánchez León 1996, 25-28.

11 Okamura 1988, 291-293; Van Dam 1992, 30-32; Sánchez León 1996, 171-176; Woods 2001, 44-49.

12 El adjetivo agrestis implica obligatoriamente un origen rural y campestre, aunque suele conllevar normalmente ciertas connotaciones peyorativas. Por su parte, el sustantivo latro es una palabra considerablemente polisémica y puede significar esencialmente bandido, mercenario, saqueador o salteador de caminos.

13 Entre las aportaciones bibliográficas más recientes en la materia, destacamos: Bravo 2013; Grant Couper 2016.

14 Aur. Vic. Caes. 39.17-20: Namque, ubi comperit Carini discessu Aelianum Amandumque per Galliam, excita manu agrestium ac latronum, quos Bagaudas incolae vocant, populatis late agris, plerasque urbium tentare, statim Maximianum, fidum amicitia, quanquam semiagrestem, militiae tamen atque ingenio bonum, imperatorem iubet. Huic postea cultu numinis Herculio cognomentum accessit, uti Valerio Iovium: unde etiam militaribus auxiliis longe in exercitum praestantibus nomen impositum. Sed Herculius, in Galliam profectus, fusis hostibus aut acceptis, quieta omnia brevi patraverat. Quo bello Carausius, Menapiae civis, factis promptioribus enituit. Dufraigne 1975, 50-51.

15 Bird 1994, XII.

16 Sánchez León 1996, 28.

17 Pocos años después de la publicación de De Caesaribus de Aurelio Víctor, Eutropio redactó para Valente otro compendio de la historia romana en latín, desde la fundación de la ciudad hasta Joviano. Este alto dignatario, que llegó a ejercer como Procónsul de Asia y como Prefecto del Pretorio de Iliria (Kretschmer 2007, 7), se hace eco en su Breviarium ab urbe condita del mismo acontecimiento (Bird 1993, VII-XI). Nos dice que una vez que Diocleciano obtuvo el control de los destinos de los romanos, se levantó en la Galia una muchedumbre de rusticani que dieron a su factio el nombre de "bacaudas". Tuvieron por líderes a Amandus y Aelianus pero pronto el emperador envió a Maximiano Hercúleo como Caesar para someterlos, quien derrotó en superfluos combates a los agrestes y devolvió la paz a las Galias. Podemos percibir que Eutropio tomó esta información de una fuente compartida $(K G)$, en su práctica totalidad, y la sintetizó sin aportar mucho más. Burgess 1995a, 111, ha descartado la posibilidad de que Eutropio pudiese copiar a Aurelio Víctor. Eutr. Brev. 9.20.3: Ita rerum Romanorum potitus, cum tumultum rusticani in Gallia concitassent et factioni suae Bacaudarum nomen imponerent, duces autem haberent Amandum et Aelianum, ad subigendos eos Maximianum Herculium Caesarem misit, qui levibus proeliis agrestes domuit et pacem Galliae reformavit. Santini 1969, 72; Sánchez León 1996, 30. 
la $K G .{ }^{18}$ En 1883 el filólogo clásico e historiador A. Enmann ${ }^{19}$ encontró similitudes y errores compartidos en ambos trabajos, también apreciables en la Historia Augusta ${ }^{20}$ por lo que postuló la existencia de una fuente común no conservada. Así, la Enmannsche Kaisergeschichte debió narrar la historia romana ${ }^{21}$ desde el 30 a.C. hasta el $357^{22}$ y quizás pudo escribirse en la Galia. ${ }^{23}$ Empero, también se ha destacado que no todo el material disponible en De Caesaribus de Aurelio Víctor y en el Breviarium de Eutropio procedería de la $K G$. Por supuesto, De Caesaribus está impregnado de retazos propios de la personalidad de Aurelio Víctor ${ }^{24}$ pero, en el caso del fragmento mencionado, parece poco verosímil que pudiera nacer de un autor africano muy posterior y escasamente familiarizado con la historia local de las Galias. Como argumento contrario, se podría esgrimir que Aurelio Víctor pudo tener acceso a informaciones históricas privilegiadas como miembro del aparato administrativo del Estado, pero sabemos que él se dedicó especialmente al ámbito jurídico, sirviendo quizás en el cuerpo de notarios o en el scrinium epistolarum, redactando rescriptos y respuestas para las delegaciones de los concilios provinciales y ciudadanos. ${ }^{25}$ Desde hace décadas, especialistas de la talla del ya mencionado $\operatorname{Bird}^{26}$ no dudan en asegurar que la $K G$ fue la fuente primordial de la que se nutrió De Caesaribus.

La $K G$ debió haber servido como fuente-guía (especialmente entre 284-337) a Aurelio Víctor y Eutropio, ${ }^{27}$ independientemente del debate que ha suscitado la datación más o menos tardía del trabajo perdido. ${ }^{28}$ Asimismo, siguiendo a R. W. Burgess, $K G$ concedió un papel primordial a los usurpadores, ${ }^{29}$ elemento que encajaría en cierto modo con la aparición en sus páginas de líderes rebeldes como Aelianus y Amandus. ${ }^{30}$ Por otra parte, y en vinculación directa con el carácter relativamente local que puede conllevar el episodio bagáudico del siglo III, se ha barajado la hipótesis de que el autor de la $K G$ fuese un historiador residente en las Galias. ${ }^{31}$

18 Para profundizar en la visión contraria, es decir, la no existencia de la $K G$, véase especialmente Den Boer 1972, 22, 55-56, 67, 110, 116-120, 124 y 187-188.

19 Enmann 1884, 337-501.

20 Rohrbacher 2016, 11.

21 Rohrbacher 2009, 709-719.

22 Barnes 1970, 13-43, consideró que la $K G$ no fue elaborada con posterioridad a 337.

23 Bird 1994, XIII.

24 Hablamos de un estilo moralizante plagado de juicios de valor y opiniones personales, asociadas a una ideología pagana, tradicionalista y senatorial. Sancho Gómez 2009, 38-39.

25 Tal y como afirma Bird 1994, VII-VIII.

26 "Despite the serious reservations of den Boer and Dufraigne most scholars nowadays accept that Aurelius Victor, like his contemporary Eutropius for the imperial section of his Breviarium, made first-hand use of only one basic source, the so-called Kaisergeschichte" (Bird 1994, XII).

27 Harries 2012, 28.

28 Bird 1973, 375-377; Burgess 1995a, 111-128.

29 En De Caesaribus podemos encontrar referencias a numerosos usurpadores del siglo III y IV. Véase entre otros, Jotapiano (29.2), Prisco (29.2), Regaliano (33.2), Aureolo (33.17), Saturnino (37.3), Bonoso (37.3), Póstumo (33.8), Leliano (33.8), Mario (33.9), Victorino (33.12), Tétrico, Tétrico II (33.14), Carausio (39.20), Calocero (41.11), Magnencio (41.23), Decencio (42.9), Nepociano (42.6) o Silvano (42.14).

30 Por supuesto, no hay ninguna evidencia documental que nos permita afirmar que estos líderes bagaudas fueron usurpadores (Southern 2015, 215; Omissi 2018, 76). Lo único que pretendemos destacar es la importancia que la $K G$ ofreció a los poderes rebeldes o sediciosos.

31 Burgess 1995a, 113. En este artículo se menciona expresamente al hipotético Eusebio de Nantes. Consúltese otro trabajo precedente del mismo autor, Burgess 1993, 495-498. Siempre y cuando consideremos que Eusebio 


\section{Kaisergeschichte: ¿una fuente utilizada por Jerónimo?}

Partiendo de la premisa inicial de que el término "bagauda" no apareció por vez primera en Aurelio Víctor sino que ya se habría registrado con anterioridad en la no conservada $K G{ }^{32}$ pasamos a analizar hasta dónde llega la influencia de la controvertida fuente común no preservada. Para Burgesss, ${ }^{33}$ las huellas de la $K G$ se pueden contemplar en Aurelio Víctor, Eutropio, Rufo Festo, Jerónimo, la Historia Augusta, el anónimo Epitome de Caesaribus, Amiano Marcelino y quizás en la Origo Constantini Imperatoris. ${ }^{34}$

No nos interesa en exceso incidir en la conocida Versio Graeca Historiae Romanae Eutropii de Peanio, ${ }^{35}$ puesto que se limitó a traducir al griego hacia el 379-380 el Breviarium de Eutropio, que por su concisión y claridad se convirtió en un texto escolar de gran éxito. No obstante, sí haremos hincapié en la aparición del término "bagauda" en el Chronicon de Jerónimo de Estridón. ${ }^{36}$

El Doctor de la Iglesia, nacido en tierras de Dalmatia, tras haberse formado en Roma y haber recorrido las Galias, vivió temporalmente como un anacoreta atraído por el ascetismo de los desiertos de Siria. Con posterioridad se instaló en Constantinopla, donde recibió lecciones de Gregorio Nacianceno. Al mismo tiempo que comenzaba a desarrollar su exégesis bíblica trilingüe, entre $380-381^{37}$ tradujo

de Nantes pudo ser el autor de la $K G$, a pesar de su nombre griego, podríamos suponer que debió escribir en latín, siguiendo las tendencias generales de la historiografía pagana latina del siglo IV, compilando breves biografías imperiales tal y como puede apreciarse en Aurelio Víctor y Eutropio. Baldini 2006, 7-18. Burgess 2005, 189, añadió que quizás Eusebio de Nantes fue solo un continuador de la $K G$ original.

32 Esta hipótesis ya fue contemplada por Minor 1996, 300, y, previamente, con más cautela, pero en la misma dirección, por Rubin 1995, 139. En los últimos años, autores como Woods 2001, 44, parecen dudar cada vez menos.

33 Burgess 1993, 491.

34 Zecchini 1993, 29-38.

35 Como su propio nombre indica, esta versio traduce y adapta el contenido textual del pasaje bagáudico, transmitiendo que se produjo un levantamiento en la Galia de campesinos rústicos que recibieron el nombre de bacaudas. Es en este punto donde el autor incluye un paréntesis explicativo y aclara que así denominaban en este territorio a los "tiranos locales". El citado paréntesis de Peanio ha generado la posibilidad de ver a los líderes de los bagaudas como potenciales usurpadores. No obstante, ha de tenerse en cuenta en primer lugar que el vocablo túpavvos puede emplearse con un sentido peyorativo (tirano, dictador, usurpador, déspota) o bien puede significar simplemente gobernador con plenos poderes. Parece que el autor oriental sintió la necesidad de especificar a sus lectores la idea que implicaba el término céltico (Minor 1975, 318-322; Bravo 1984, 262-263; Minor 1996, 297-307), pero no sabemos hasta qué punto un escritor griego muy posterior a los hechos podía estar familiarizado con este tipo de lenguas. Sin duda, esta adaptación griega del texto de Eutropio ha suscitado un gran interés historiográfico pero debe puntualizarse que Peanio asocia la expresión

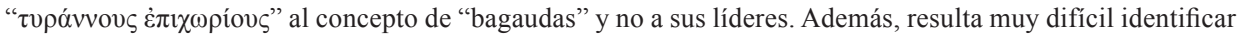
si ese paréntesis responde a una explicación fundada en un mayor conocimiento de causa o bien se trata solamente de una deducción espontánea. Resulta obvio que la traducción de Peanio es relativamente libre

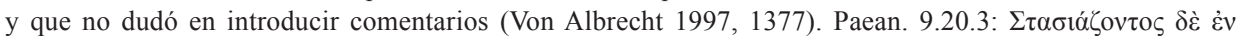

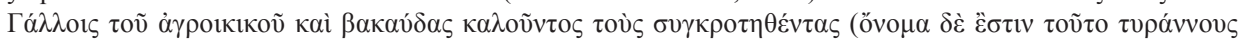

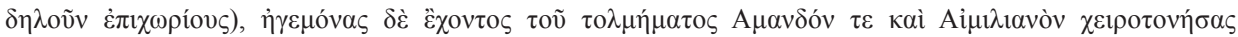

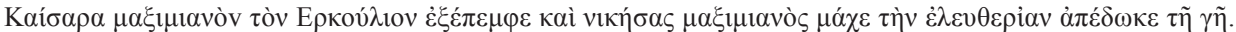
Droysen 1879, 163; MGH, AA II; Sánchez León 1996, 32. Sobre la posibilidad de que Amandus y Aelianus fuesen realmente usurpadores, vid. Sánchez León 1986, 429-431, y 1996, 171-176; Drinkwater 1989, 198; Minor 1997, 173-174.

36 Rebenich 2002.

37 Burgess 1995b, 351. 


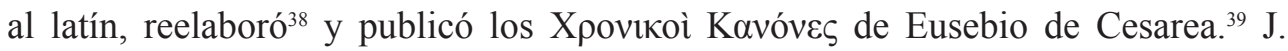
C. Sánchez León ${ }^{40}$ ha considerado que el fragmento que menciona a los bagaudas del siglo III está tomado de Eutropio, ${ }^{41}$ si bien es cierto que ha dejado abierta la posibilidad de que Jerónimo pudiese haber manejado también a Aurelio Víctor y a la $K G$. En cuanto a la relación entre Jerónimo y la $K G$, Burgess ${ }^{42}$ coincidiendo con un viejo artículo de R. Helm ${ }^{43}$ rechazó abiertamente la influencia unívoca de Eutropio en la crónica del presbítero. Es más, no titubeó a la hora de afirmar que la práctica totalidad de las informaciones ofrecidas por Eutropio ya estaban en la $K G$, por lo que Jerónimo bien pudo haber usado solamente la $K G .^{44}$

\section{Los Xpovıкò̀ Kavóves de Eusebio de Cesarea}

Eusebio de Cesarea es realmente el padre de la Historia de la Iglesia, tal y como lo definía P. L. Maier. ${ }^{45}$ Nacido hacia el 260 en la famosa urbe palestina de Caesarea Maritima, se vio notoriamente involucrado durante la "Gran Persecución" 46 contra los cristianos, pero sobrevivió para convertirse con posterioridad en obispo de su ciudad. Consejero y panegirista de Constantino, ${ }^{47}$ afrontó la convulsa controversia arriana que comprometió por momentos incluso su propia ortodoxia. En cuanto a sus numerosos escritos, ${ }^{48}$ no nos centraremos en sus trabajos apologéticos, polémicos, doctrinales o exegéticos, ni tampoco en sus misivas, puesto que nos concierne únicamente su aportación histórica. Así pues, obviando la célebre

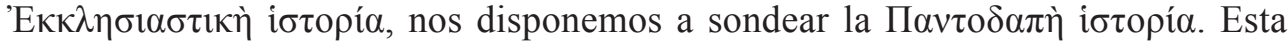
obra de cronología, que cubría la "historia universal" desde Abraham hasta los vicennalia de Constantino en 325, estaba integrada por dos partes: una parte inicial de cronografía ${ }^{49}$ y otra segunda compuesta por tablas cronológicas sincrónicas. Perdida en su conjunto, podemos reconstruirla con muchas dificultades ${ }^{50}$ a través de

38 El propio Jerónimo dice en el prefacio que no se ha limitado solamente a traducir el texto griego de Eusebio, sino que ha añadido mucho material procedente de Suetonio (De viris illustribus) y otros historiadores latinos. Burgess 1999, 115.

39 Sánchez León 1996, 35-36. Hieron. Chron. a. Abr. 2303. (286-288): Diocletianus in consortium regni Herculium Maximianum adsumit. Qui rusticorum multitudine opressa, quae factioni suae Bacaudarum nomen indiderat, pacem Galliis reddidit. Helm 1956, 225.

40 Sánchez León 1996, 36.

41 Ya Mommsen 1850, 606-632, había establecido esta conclusión a mediados del siglo XIX.

42 Burgess 1995b, 351.

43 Helm 1927, 138-170, 303-305. Véase también Ratti 1997, 479-508, y 2001, 425-450, que descartó la posibilidad de que Jerónimo usara a Eutropio para la narración de los hechos acontecidos entre 357-364.

44 Burgess 1995b, 356; 1999, 115, y 2005, 166. Afirma: "One of the historians that has been identified by modern historians as a major source for Jerome is Eutropius, but this has proved to be incorrect and it has been conclusively demonstrated that this source was not Eutropius, but Eutropius' source, the Kaisergeschichte" (Burgess 1999, 115).

Maier 1999, 9.

46 Schott 2008, 136-165.

47 Barnes 1981.

48 PG, vols. 19-24. Estos seis volúmenes confirman el carácter prolífico de su obra.

49 Esta primera parte de la crónica de Eusebio ofrecía una historia de los caldeos, asirios, judíos, egipcios, griegos y romanos.

50 Burgess 1999, 22: 'Neither translation, however, is a certain guide to Eusebius' original, since Jerome and the Armenian translation often differ greatly in their content, translation and chronology, making it difficult if not impossible to recover the original from a simple comparison of the two". 
dos epítomes siríacos ${ }^{51}$ una traducción armenia ${ }^{52}$ y la edición latina de Jerónimo, ${ }^{53}$ que preservó los Xpovikoì Kavóvec. ${ }^{54}$

Sobre la datación de los Xpovikoì Kavóveৎ de Eusebio, nuevamente Burgess ${ }^{55}$ ha considerado la posible existencia de una primera edición anterior a 325, completada después de $306^{56}$ y antes de $313 .{ }^{57}$ Después del cese de la "Gran persecución", Eusebio probablemente actualizó sus cánones hasta configurar una última edición en 325, cuyo impacto movió a Jerónimo a emprender su traducción al latín décadas después $(381){ }^{58}$

\section{5. ¿Pudo Eusebio de Cesarea usar la Kaisergeschichte?}

Eusebio utilizó un considerable número de fuentes para abordar sus trabajos históricos, perfectamente resumidos en el libro de A. J. Carriker. ${ }^{59}$ No obstante, si analizamos cada uno de los nombres retratados, pronto llegaremos a la conclusión de que todas sus fuentes son griegas. Abideno, Alejandro Polihistor, Cástor de Rodas, Cefalión, Diodoro Sículo, Dionisio de Halicarnaso, Filón de Biblos, Flavio Josefo, Flegón de Trales, Manetón o Sexto Julio Africano escribieron sus obras en griego.

¿Significa esto que Eusebio de Cesarea tan solo hablaba griego y no pudo manejar ninguna fuente latina? Partiendo del trabajo de J. B. Torres Guerra, ${ }^{60}$ nos decantamos en sentido negativo, puesto que Eusebio seguramente habló arameo como oriundo de la Palestina del momento. Además, sabemos que poseyó los suficientes conocimientos en lengua latina como para traducir al griego un rescripto. ${ }^{61}$ Aun así, esto no implica que el obispo fuese capaz de expresarse con fluidez en latín ni tampoco que acostumbrara a leer latín. De hecho, probablemente estudió a Tertuliano en una versión griega. ${ }^{62}$

Dicho esto, parece realmente difícil que Eusebio de Cesarea pudiera conocer e interpretar una fuente occidental como la Kaisergeschichte. Pero, igualmente, existen razones de carácter cronológico que imposibilitan esta hipótesis. Si la $K G$ fue elaborada entre 337-357 y los Xpovikoì Kavóveৎ no son posteriores a 325 , la expectativa de que Eusebio empleara dicha fuente resulta completamente inviable.

\footnotetext{
51 Integrados en Chron. 724 y en la crónica del Pseudo-Dionisio de Tel-Mahre. Keseling 1926/1927.

52 Consúltese la edición alemana del orientalista Josef Karst (1911). La primera parte o Chronographia concluye abruptamente y está incompleta.

53 Existen discrepancias notorias entre las tablas cronológicas de Jerónimo y la traducción armenia, sobre todo en materia de datación.

54 La segunda parte de la crónica contenía unas tablas que concentraban fechas y eventos.

55 Burgess 1997, 471.

56 A diferencia de Wallace-Hadrill 1955, 248-253, Mosshammer 1979, 38, 61-63 y 75; Burgess 1997, 482.

57 Burgess 1997, 495.

58 Kelly 2008, 90.

59 Carriker 2003, 139-154.

60 Torres Guerra 2013, 13-24.

HE. 4.8.8.

62 Podemos extraer todas estas consideraciones de la lectura del ya citado artículo de Torres Guerra 2013, 15.
} 


\section{6. ¿Pudo entonces Eusebio de Cesarea usar la palabra "bagauda" en sus Xpovuкoì Kavóves sin tener acceso a la Kaisergeschichte?}

Si recurrimos a la reconstrucción hipotética de la obra de Eusebio de Cesarea a través de los extractos de la cronografía posterior de la escuela bizantina ${ }^{63}$ Jorge Sincelo ${ }^{64}$ "el Monje" compiló una historia del mundo entre $806-814^{65}$ desde Adán hasta Diocleciano, donde no aparece en ningún caso la palabra "bagauda". Teófanes el Confesor continuó poco después ${ }^{66}$ la crónica de Sincelo, narrando la historia romana desde Diocleciano hasta Miguel I Rangabé. A diferencia de su predecesor, Teófanes sí hizo referencia a Aelianus y Amandus, pero sin mencionar a los bagaudas. ${ }^{67}$ Teniendo la certeza de que Jorge Sincelo usó y citó la crónica de Eusebio, ${ }^{68}$ podría existir la posibilidad de que también Teófanes lo hiciera, y por tanto, se abriría la hipótesis de la inclusión de esta información en los cánones del obispo de Cesarea.

Sánchez León indicó de manera poco aclaratoria que Teófanes conoció la obra de "Eusebio-Jerónimo", ${ }^{69}$ añadiendo que este último nunca incluyó los nombres de los caudillos de los bagaudas, que sí aparecen en el pasaje de Teófanes. Sin embargo, debería tenerse en cuenta, siguiendo a C. Mango y R. Scott, ${ }^{70}$ que Teófanes se sirvió sobre todo de la Historia Tripartita y la Historia Ecclesiastica de Teodoro el lector, aunque también manejó muchas otras fuentes orientales, así como alguna traducción griega de Eutropio. Si no pudo disponer de la crónica de Eusebio, ${ }^{71}$ podríamos suponer que Jorge Sincelo no nombró a los bagaudas tanto porque su crónica concluía justo en los albores del reinado de Diocleciano como porque Eusebio nunca los citó. De igual modo, podríamos determinar que Teófanes el Confesor aludió a Aelianus y Amandus porque lo copió de una versión griega de Eutropio.

Por su parte, la versión armenia de la crónica de Eusebio, traducida al alemán en 1911 por el filólogo orientalista J. Karst en el quinto volumen sobre los trabajos del obispo de Cesarea, no incluye ningún tipo de información sobre los bagaudas galos de la etapa dioclecianea. La primera parte (Die Chronographie) ${ }^{72}$ finaliza de manera incompleta ${ }^{73}$ y los cánones (Der kanon) ${ }^{74}$ tan solo apuntan la muerte de Numeriano en Tracia y la derrota definitiva de Carino ${ }^{75}$ en Cornacum. ${ }^{76} \mathrm{~A}$ su vez, se inserta una

\footnotetext{
Treadgold 2013.

CSHB, 22. Adler - Tuffin 2002.

65 Pummer 2002, 399. Atkinson 2012, 148, especifica más aún las fechas durante las cuales Jorge Sincelo trabajó en esta obra: 808-814.

66 Sánchez León 1996, 32.

67 Sánchez León 1996, 33 y 123. El pasaje del cronista bizantino destaca los problemas que habían provocado en la Galia estos dos caudillos, por lo que Maximiano Hercúleo se dispuso a emprender una expedición punitiva

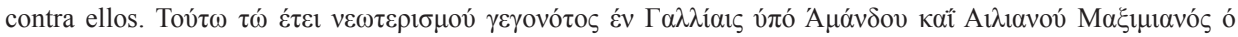

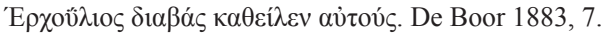

68 Pummer 2002, 399.

69 Sánchez León 1996, 33.

70 Mango - Scott 1997, LXXII-XCV.

71 Mango - Scott 1997, LIV.

72 Karst 1911, 1-155.

73 "Hier, in der Mitte des betr. armenischen Worts, endigt die Seite in Mss. Der Schlußteil des Verzeichnisses und der Anfang des Kanon sind ausgefallen” (Karst 1911, 155).

74 Karst 1911, 156-227.

75 "Nach des Karos Tode im Zwischen-stromlande erfolgte unterdessen auch die Tötung des Nomerianos in Thrakien, und ebenso die des Karinos in dem Kriege des Kornakos" (Karst 1911, 227).

76 La muerte de Carino en Cornacum contradice la visión tradicional que afirma que falleció en la batalla del
} 
breve mención sobre la alianza posterior entre Constantino y Maximiano durante la Segunda tetrarquía. ${ }^{77}$ En cuanto a los dos epítomes siríacos, no hay vestigio alguno del relato bagáudico ni en el Chronicon miscellaneum ad annum Domini 724 pertinens ${ }^{78}$ ni en la crónica del Pseudo-Dionisio de Tel-Mahre. ${ }^{79}$

Analizando con perspectiva todos estos elementos, concluimos que Eusebio de Cesarea no pudo incorporar ninguna referencia acerca de estos acontecimientos occidentales precedentes por tres razones básicas: 1) La cronología manejada imposibilita la hipótesis de que Eusebio conociera la $K G$. Asimismo, la práctica totalidad de las fuentes usadas por este autor fueron griegas. 2) La hipotética reconstrucción de su crónica a través de los epítomes siríacos, la versión armenia y el trabajo posterior del cronista bizantino Jorge Sincelo corroboran la no aparición del término "bagauda" en los Xpovıкoì Kavóves. 3) Los autores orientales greco-parlantes no conocieron estos pasajes históricos hasta la difusión de las traducciones al griego de Eutropio, ya en el último tercio del siglo IV. ${ }^{80}$ Por consiguiente, la investigación nos fuerza a considerar con bastante firmeza que si el término "bagauda" se inscribe en el Chronicon de Jerónimo es debido a una adición propia del autor de la Vulgata, ${ }^{81}$ que consultó muchas otras fuentes ${ }^{82}$ entre las cuales se encontraba la $K G$.

\section{Conclusiones}

En la actualidad, pocos investigadores dudan sobre la existencia de la Enmannsche Kaisergeschichte. Esta "historia de los emperadores", no conservada, sirvió de fuente común a varias obras históricas posteriores, como el De Caesaribus de Aurelio Víctor $^{83}$ y el Breviarium de Eutropio. Empero, la primera incógnita historiográfica a despejar, en relación con la aparición del término "bagauda" en el trabajo del autor africano, consistiría en identificar si esta alusión concreta fue copiada de la $K G$ o bien fue incluida por el propio Víctor. A nuestro juicio, la más que probable procedencia occidental (Galia) del anónimo autor de la $K G$ y las referencias recurrentes a usurpadores y poderes rebeldes regionales serían una razón de peso para considerar que el pasaje sobre Aelianus y Amandus está extraído de la fuente perdida, y que no se trata de un añadido de un autor más tardío y menos familiarizado con la historia local de las Galias en el período dioclecianeo.

Más allá de las menciones explícitas del mismo episodio registradas en el breviario de Eutropio o en la versión griega de Peanio, nos interesa profundizar en el Chronicon

Margus. Kovács 2011, 241-252. En este artículo, se defiende que Carino pereció después de la famosa batalla, cerca de esta fortaleza panonia mientras intentaba huir.

77 "Konstandinos und Maximianos wurden zu Kaisern und Mitgenossen der Herrschaft zugeschrieben" (Karst 1911, 227).

78 CSCO ser. 3/4; con traducción latina por Chabot 1903, 61-119: Chronicon miscellaneum ad annum Domini 724 pertinens, 99-100.

79 CSCO, vol. 121, Chabot 1949, 110: Incerti auctoris Chronicon pseudo-Dionysianum vulgo dictum, I. También conocida como crónica de Zuqnin.

80 Cameron 2011, 665. El académico británico se cuestiona por qué se tradujo al griego la obra de Eutropio y no directamente la $K G$.

81 Así lo consideró indirectamente R. Helm en su edición de 1956 (Eusebius Werke 7: Die Chronik des Hieronymus), marcando el pasaje con un asterisco; esto implicaba la muy posible inclusión de Jerónimo.

82 Burgess 1999, 115-118.

83 Barnes 1970, 20. 
de Jerónimo. Si el Doctor de la Iglesia compuso su crónica a través de la traducción de los Xроvıко̀ Kavóves o tablas cronológicas de Eusebio de Cesarea, se abre así una nueva disyuntiva (hasta ahora no resuelta en la bibliografía específica existente sobre el bagaudismo) entre dos posibilidades: a) Jerónimo copió a Eusebio, por lo que Eusebio también utilizó previamente el término "bagauda". b) Jerónimo no tomó estas informaciones de los Xpovikoì Kavóveৎ y las extrajo de otras fuentes.

Mediante el estudio del repertorio específico de fuentes manejado por Eusebio de Cesarea, parece realmente difícil contemplar que el obispo pudiera tener acceso a esta narración. Asimismo, hay razones de orden cronológico que imposibilitan que Eusebio consultase la $K G$. Por último, el rastreo de la "historia universal" del prelado palestino a través de los epítomes siríacos, la versión armenia y la crónica de Jorge Sincelo nos corrobora la ausencia del término "bagauda" en la $\Pi \alpha \nu \tau o \delta \alpha \pi \grave{~ i \sigma \tau o \rho i ́ \alpha . ~}$

Habiendo llegado a la conclusión de que Jerónimo de Estridón no copió el extracto (en el que aparece el vocablo "bagauda") de Eusebio de Cesarea, tan solo resta la indagación sobre la fuente de procedencia que le llevó a escribir sobre los bagaudas galos de 285 . En este sentido, todo apunta nuevamente a la $K G$, en tanto en cuanto las aparentes similitudes con el pasaje de Eutropio no son óbice suficiente para rechazar que Jerónimo pudiera consultar directamente la fuente original de la que también se nutre el compilador del Breviarium.

\section{Referencias bibliográficas}

Adler, W. - Tuffin, P. (2002): The Chronography of George Synkellos: A Byzantine Chronicle of Universal History from the Creation, Oxford-New York.

Atkinson, K. (2012): Queen Salome: Jerusalem's Warrior Monarch of the First Century B.C.E., Jefferson (NC).

Baldini, A. (2006): "Storia senza storie (IV-V secolo d. C.)", Classica 19/1, 7-18 (https://doi. org/10.24277/classica.v19i1.100).

Barnes, $\mathrm{T}$.

(1970): “The Lost Kaisergeschichte and the Latin Historical Tradition", [en] G. Alföldy (ed.), Bonner Historia Augusta Colloquium 1968/69, Bonn, 13-43.

(1981): Constantine and Eusebius, Cambridge (MA).

Bird, H. W.

(1973): "Further Observations on the Dating of Enmann's Kaisergeschichte", The Classical Quarterly 23/2, 375-377 (https://doi.org/10.1017/S0009838800036892).

(1984): Sextus Aurelius Victor: A Historiographical Study, Liverpool.

(1993): Eutropius: Breviarium, Liverpool (https://doi.org/10.3828/978-0-85323-208-7).

(1994): Aurelius Victor: De Caesaribus, Liverpool (https://doi.org/10.3828/978-0-85323218-6).

Bravo, G.

(1984): “Acta Bagaudica (I): sobre quiénes eran bagaudas y su posible identificación en los textos tardíos", Gerión 2, 251-264.

(2013): “¿Explotados o marginados? Sobre la entidad social de la bagauda galohispánica", [en] R. Gónzález Salinero (ed.), Marginados sociales y religiosos en la Hispania tardorromana y visigoda, Madrid-Salamanca, 65-83. 
Burgess, R. W.

(1993): "Principes cum Tyrannis: Two Studies on the Kaisergeschichte and its Tradition", The Classical Quarterly 43/2, 491-500 (https://doi.org/10.1017/S0009838800040039).

(1995a): "On the Date of the Kaisergeschichte", Classical Philology 90/2, 111-128 (https://doi.org/10.1086/367453).

(1995b): "Jerome and the Kaisergeschichte", Historia 44, 349-369.

(1997): “The Dates and Editions of Eusebius' Chronici canones and Historia ecclesiastica", The Journal of Theological Studies 48, 471-504 (https://doi.org/10.1093/jts/48.2.471).

(1999): Studies in Eusebian and Post-Eusebian Chronography, Stuttgart.

(2005): "A Common Source for Jerome, Eutropius, Festus, Ammianus, and the Epitome de Caesaribus between 358 and 378, along with Further Thoughts on the Date and Nature of the Kaisergeschichte", Classical Philology 100/2, 166-192 (https://doi. org/10.1086/432844).

Cameron, A. (2011): The Last Pagans of Rome, Oxford (https://doi.org/10.1093/ acprof:oso/9780199747276.001.0001).

Carriker, A. J. (2003): The Library of Eusebius of Caesarea (=Vigiliae Christianae, Supplements 67), Leiden (https://doi.org/10.1163/9789047402312).

Czúth, B. (1965): Die Quellen der Geschichte der Bagauden, Szeged.

Den Boer, W. (1972): Some Minor Roman Historians, Leiden.

Drinkwater, J. F. (1989): "Patronage in Roman Gaul and the Problem of the Bagaudae", [en] A. Wallace-Hadrill (ed.), Patronage in Ancient Society, London, 189-203.

Enmann, A. (1884): "Eine verlorene Geschichte der römischen Kaiser und das Buch De viris illustribus urbis Romae", Philologus Suppl. 4/3, 337-501.

Errington, R. M. (2006): Roman Imperial Policy from Julian to Theodosius, Chapel Hill.

Grant Couper, J. (2016): "Gallic Insurgencies? Annihilating the Bagaudae", [en] T. Howe - L. L. Brice (eds.), Brill's Companion to Insurgency and Terrorism in the Ancient Mediterranean, Leiden-Boston, 312-343 (https://doi.org/10.1163/9789004284739_012).

Harries, J. (2012): Imperial Rome AD 284 to 363. The New Empire, Edinburgh.

Helm, R.

(1927): "Hieronymus und Eutrop", Rheinisches Museum für Philologie 76/2, 138-170; 76/3, 254-306.

(1956): Eusebius Werke. Siebenter Band. Die Chronik des Hieronymus, Berlin.

Karst, J. (1911): Eusebius Werke. Fünfter Band. Die Chronik aus dem armenischen Übersetzt mit textkritischem Commentar, Leipzig.

Kelly, G. (2008): Ammianus Marcellinus: The Allusive Historian, Cambridge.

Keseling, P. (1926/1927): "Die Chronik des Eusebius in der syrischen Überlieferung”, Oriens Christianus 1, 1926/27, 23-48, 223-241; 2, 1927, 33-56.

Kovács, P. (2011): "The battle of Margum or where Emperor Carinus died", Acta Musei Napocensis 45-46/1, 241-252.

Kretschmer, M. T. (2007): Rewriting Roman History in the Middle Ages: The Historia Romana and the Manuscript Bamberg, Hist. 3, Leiden-Boston (https://doi.org/10.1163/ ej.9789004157101.i-428).

Maier, P. L. (1999): Eusebius: The Church History, Grand Rapids.

Mango, C. - Scott, R. (1997): The Chronicle of Theophanes Confessor. Byzantine and Near Eastern History AD 284-813, Oxford.

Minor, C. E.

(1975): "Bagaudae or Bacaudae", Traditio 31, 318-322 (https://doi.org/10.1017/ S0362152900011387). 
(1996): “Bacaudae: A Reconsideration", Traditio 51, 297-307 (https://doi.org/10.1017/ S0362152900013465).

(1997): "Reclassifying the Bacaudae: Some Reasons for Caution", The Ancient World 28/2, 171-181.

Mommsen, T. (1850): "Über die Quellen der Chronik des Hieronymus", [en] Abhandlungen der sächsischen Gesellschaft der Wissenschaften 2, Leipzig, 669-693.

Mosshammer, A. (1979): The Chronicle of Eusebius and Greek Chronographic Tradition, Lewisburg.

Okamura, L. (1988): "Social Disturbances in Late Roman Gaul: Deserters, Rebels and Bagaudae", [en] T. Yuge - M. Doi (eds.), Forms of Control and Subordination in Antiquity, Leiden-New York-København-Köln, 288-302.

Omissi, A. (2018): Emperors and Usurpers in the Later Roman Empire: Civil War, Panegyric and the Construction of Legitimacy, Oxford (https://doi.org/10.1093/ oso/9780198824824.001.0001).

Pummer, R. (2002): Early Christian Authors on Samaritans and Samaritanism, Tübingen.

Ratti, S.

(1997): "Jérôme et Nicomaque Flavien: Sur les sources de la Chronique pour les années 357-64", Historia 46, 479-508.

(2001): "Les sources de la Chronique de Jérôme pour les années 357-64: Nouveaux éléments", [en] B. Pouderon - Y. Duval (dirs.), L'historiographie de l'Église des premiers siècles (=Théologie Historique 114), Paris, 425-450.

Rebenich, S. (2002): Jerome: The Early Church Father, London-New York.

Rohrbacher, D.

(2002): The Historians of Late Antiquity, London.

(2009): "Enmann's "Kaisergeschichte" from Augustus to Domitian", Latomus 68/3, 709-719. (2016): The Play of Allusion in the Historia Augusta, Madison.

Rubin, Z. (1995): "Mass Movements in Late Antiquity: Appearances and Realities", [en] I. Malkin - Z. W. Rubinsohn (eds.), Leaders and Masses in the Roman World. Studies in Honor of Zvi Yavetz (=Mnemosyne Suppl. 139), Leiden-New York-Köln, 129-188 (https://doi.org/10.1163/9789004329447_009).

Sánchez León, J. C.

(1986): "Una nota sobre las monedas atribuidas a Amandus y Aelianus, caudillos de los Bagaudas en el siglo III d. C.”, Studia Zamorensia Historica 7, 429-431.

(1996): Les sources de l'histoire des Bagaudes. Traduction et Commentaire, Paris.

Sancho Gómez, M. (2009): “Actitud y pensamiento de Sexto Aurelio Víctor: algunos rasgos de un historiador en la Roma tardía", Polis 21, 37-57.

Schott, J. M. (2008): Christianity, Empire, and the Making of Religion in Late Antiquity, Philadelphia.

Southern, P. (2015): The Roman Empire from Severus to Constantine, London-New York (https://doi.org/10.4324/9781315713083).

Starr, C. G. (1956): “Aurelius Victor: Historian of Empire”, The American Historical Review 61/3, 574-586 (http://dx.doi.org/10.2307/1847591).

Torres Guerra, J. B. (2013): “The Bilingual Emperor: Eusebius of Caesarea's Vita Constantini", Talanta 45, 13-24.

Treadgold, W. (2013): The Middle Byzantine Historians, New York (https://doi. org/10.1057/9781137280862).

Van Dam, R. (1992): Leadership and Community in Late Antique Gaul, Berkeley-Los Angeles- London. 
Von Albrecht, M. (1997): A History of Roman Literature: From Livius Andronicus to Boethius, vol. 2, Leiden-New York-Köln (https://doi.org/10.1163/9789004329904).

Wallace-Hadrill, D. S. (1955): “The Eusebian Chronicle: The Extent and Date of Composition of its Early Editions", The Journal of Theological Studies 6, 248-253 (https://doi. org/10.1093/jts/VI.2.248).

Woods, D. (2001): “Amandus: Rustic Rebel or Pirate Prince?”, Ancient History Bulletin 15/1, 44-49.

Zecchini, G. (1993): “L'origo Constantini Imperatoris", [en] G. Zecchini (ed.), Ricerche di storiografia latina tardoantica, Roma, 29-38. 